\title{
Skin sympathetic nerve activity in Guillain-Barré syndrome: a microneurographic study
}

Koji Yamamoto, Gen Sobue, Satoshi Iwase, Masaaki Nagamatsu, Tadaaki Mano, Terunori Mitsuma

Fourth Department of Internal Medicine, Aichi Medical University

K Yamamoto

T Mitsuma

Department of Neurology, School of Medicine, Nagoya University

G Sobue

M Nagamatsu

Department of

Autonomic and

Behavioral

Neurosciences,

Division of Higher

Nervous Control,

Research Institute of

Environmental

Medicine, Nagoya

University, Nagoya,

Japan

$S$ Iwase

T Mano

Correspondence to:

Dr K Yamamoto, The

Fourth Department of

Internal Medicine, Aichi

Medical University, 21,

Karimata, Yazako,

Nagakute-cho, Aichi 480-11,

Japan.

Received 13 November 1996 and in revised form

9 April 1997

Accepted 11 April 1997

\begin{abstract}
To assess autonomic dysfunction, skin sympathetic nerve activity (SSNA) of four patients with Guillain-Barré syndrome was microneurographically studied in the acute and remission phase. Autonomic symptoms such as sinus tachycardia, palmar hyperhidrosis, hypertension, and orthostatic hypotension were present in the acute phase, but all subsided during remission. Basal resting SSNA and the responses to various physical and mental stimuli were all increased in the acute phase and returned almost to normal during remission. Rate of response in sweat rate and blood flow against SSNA were kept proportionally constant during both the acute and remission phases. These findings suggest that some autonomic nerve symptoms of Guillain-Barré syndrome, particularly during the acute phase, are due to increased SSNA.
\end{abstract}

\section{(F Neurol Neurosurg Psychiatry 1997;63:537-541)}

Keywords: Guillain-Barré syndrome; skin sympathetic nerve activity; autonomic dysfunction; microneurography

Guillain-Barré syndrome ${ }^{12}$ shows various autonomic nerve symptoms, including hypertension, ${ }^{3}$ tachycardia, ${ }^{34}$ orthostatic hypotension, ${ }^{5}$ arrhythmia, ${ }^{3}$ gastrointestinal symptoms, ${ }^{5-7}$ and palmar hyperhidrosis. ${ }^{5-8}$ These changes are found in acute Guillain-Barré syndrome, and sometimes become determinants of an unfavourable prognosis. Fagius et al used microneurography to measure the activity of sympathetic nerves innervating muscles (muscle sympathetic nerve activity; MSNA), which plays a key part in blood pressure regulation ${ }^{9}$ in patients with Guillain-Barré syndrome and increases in the acute phase. In the present study, we quantitatively evaluated autonomic functions and microneurographycally assessed the skin sympathetic nerve activity (SSNA) ${ }^{10-16}$ in four patients with classic Guillain-Barré syndrome to investigate the pathogenesis of autonomic nerve symptoms in this disease. SSNA is a major regulator for sweating and skin blood flow. Changes of autonomic dysfunctions and SSNA were assessed by comparison between the acute and remission phases of Guillain-Barré syndrome.

\section{Subjects and methods}

PATIENTS

Four patients with Guillain-Barré syndrome (three men and one woman ranging from 21 to 56 years in age) were studied. The table shows their clinical profiles. All patients satisfied the NINCDS diagnostic criteria for Guillain-Barré syndrome. ${ }^{1}$ Two patients had influenza-like symptoms, and one had diarrhoea as prodromal episodes. Guillain-Barré syndrome commenced with weakness of the lower limbs and reached a peak after two to five days. Motor paralysis was mild in two patients, who could walk with support, but more prominent in the other two, who could not stand unaided. Deep tendon reflexes were lost, and mild to moderate sensory disturbance was present, predominantly in the distal parts of the legs. Autonomic dysfunction consisted of sinus tachycardia, hypertension, and palmoplantar hyperhidrosis in all patients, as well as orthostatic hypotension to various degrees in two patients. Muscle strength had recovered well in all patients by three to six months. Microneurographic recordings were made at eight to 12 days after the onset of Guillain-Barré syndrome (acute phase) and at two to six months (remission phase). Heart rate and blood pressure were measured in the supine position early every morning. In the acute phase of the disease, sinus tachycardia, palmoplantar hyperhidrosis, and hypertension were seen in all patients, whereas orthostatic hypotension, difficulty in urination, abdominal distention, and constipation developed in one patient each. These autonomic dysfunctions regressed with the remission of Guillain-Barré syndrome, although they were prominent in the acute phase (fig 1, table).

Before SSNA recording, the purpose and methods of this study were explained to the patients and informed consent was obtained. This study was approved by the ethics committee on human research of the Research Institute of Environmental Medicine, Nagoya University. 

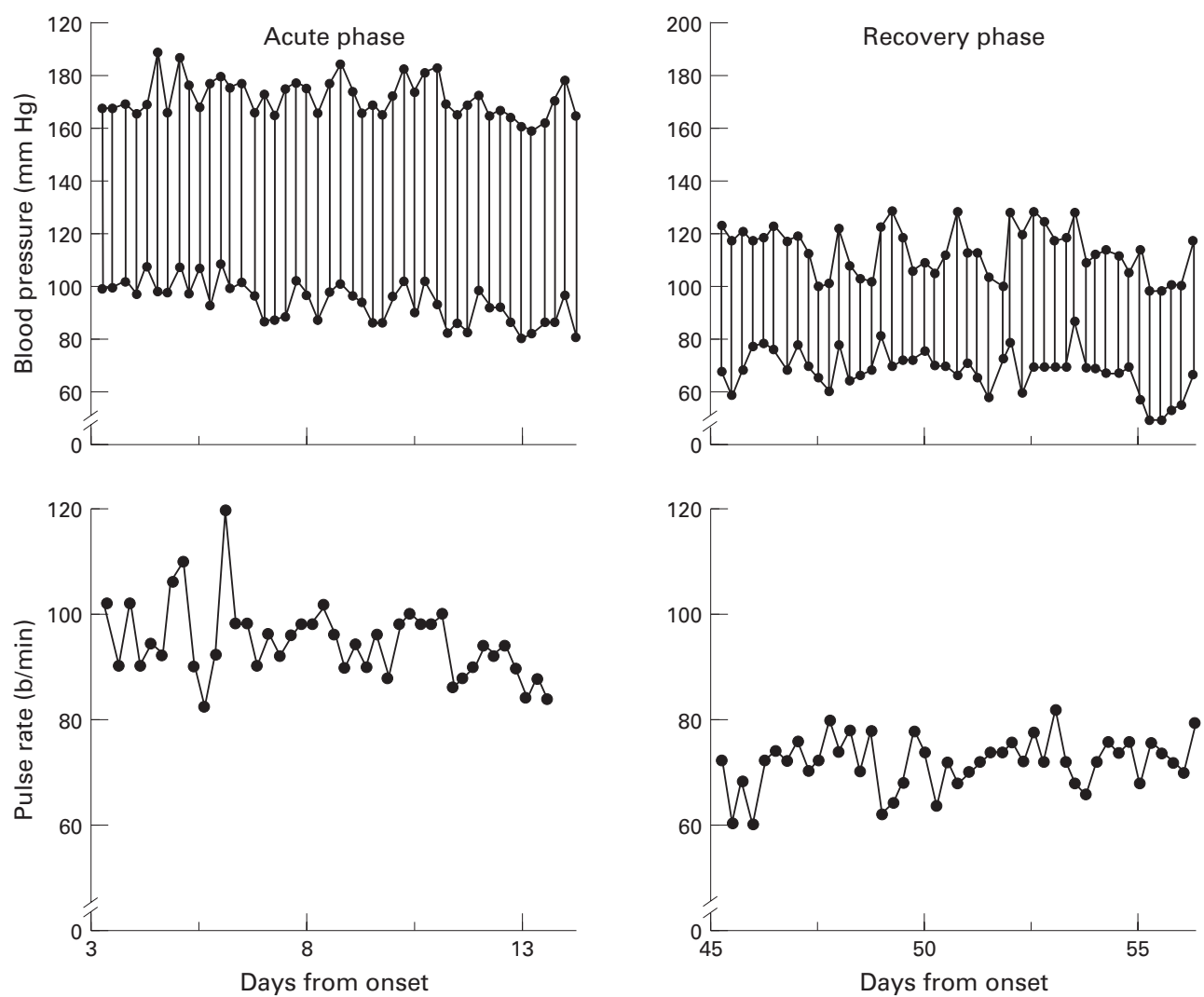

Figure 1 Pulse rate and blood pressure during acute Guillain-Barré syndrome and in remission (a representative case) Tachycardia was seen in the acute phase and resolved during remission. Hypertension was seen in the acute phase and resolved during remission.

RECORDING OF SKIN SYMPATHETIC NERVE ACTIVITY

The patient lay supine on a bed with the legs extended, and recording was performed in a climatic chamber at $25^{\circ} \mathrm{CRt}$ and $40 \%$ humidity with blockage of sound and light stimuli. Without anaesthesia, we transdermally inserted a tungsten microelectrode with a $1 \mu \mathrm{m}$ diameter tip and an impedance of 3-5 M $\Omega$ into the median nerve at the cubital fossa to elicit and record SSNA, which represents the activity of the sympathetic postganglionic efferent fibres supplying the skin of the palm of the hand. The SSNA was identified as described previously ${ }^{11}{ }^{17}$ according to the following criteria: (1) pulse asynchronous, irregular burst activity lasting for $300-500 \mathrm{~ms}$; (2) an increase of activity in response to mental/physical stress (sound, mental arithmetic, and cold); (3) reflex bursts of a fixed latency (around 0.8-1.1 s) in response to electrical stimulation; (4) a decrease in skin blood flow or sweating after the bursts; and (5) environmental temperature dependence with minimal activity at a neutral temperature $\left(24-26^{\circ} \mathrm{C}\right)$ and an increase at higher or lower temperatures. The number of discharges per minute was defined as the SSNA burst rate. Both the resting basal SSNA (number of bursts/min) and the responsiveness of SSNA to various stimuli (the maximal poststimulation value divided by the mean resting basal activity) were determined.

\section{LOADING TEST}

In addition to recording during the resting condition, we conducted the loading test according to a previously described set protocol $^{11{ }^{17-18}}$ to standardise the recording conditions. Spontaneous activity (resting SSNA) was recorded for 10 minutes at rest after at least 30 minutes of resting in the supine position. Then the following loading stimuli were applied: (1) mental arithmetic (consecutively subtracting 7 from 100 without vocalisation), (2) loud noise (a starting pistol), (3)

Clinical profile of the patients

\begin{tabular}{|c|c|c|c|c|c|c|c|c|c|c|c|c|c|c|c|c|}
\hline \multirow[b]{2}{*}{ Patient } & \multirow{2}{*}{$\begin{array}{l}\text { Age } \\
(y) / \\
\text { sex }\end{array}$} & \multirow[b]{2}{*}{ Prodrome } & \multirow[b]{2}{*}{$\begin{array}{l}\text { Grade of } \\
\text { symptom * }\end{array}$} & \multirow[b]{2}{*}{ DTRst } & \multirow[b]{2}{*}{$\begin{array}{l}\text { Pathological } \\
\text { reflex }\end{array}$} & \multirow[b]{2}{*}{$\begin{array}{l}\text { Sensory } \\
\text { disturbancef }\end{array}$} & \multicolumn{2}{|l|}{ CSFS } & \multicolumn{2}{|c|}{ Hyperhidrosis } & \multicolumn{2}{|c|}{$\begin{array}{l}\text { Orthostatic } \\
\text { hypotension } \|\end{array}$} & \multicolumn{2}{|c|}{$\begin{array}{l}\text { Difficulty in } \\
\text { urination }\end{array}$} & \multicolumn{2}{|c|}{$\begin{array}{l}\text { Sinus } \\
\text { tachycardia }\end{array}$} \\
\hline & & & & & & & $\begin{array}{l}\text { Cells } \\
\mathrm{C}^{\left(\mathrm{mm} \mathrm{m}^{3}\right.}\end{array}$ & $\begin{array}{l}\text { Protein } \\
\text { (mg/dl) }\end{array}$ & $\begin{array}{l}\text { Acute } \\
\text { phase }\end{array}$ & $\begin{array}{l}\text { Remission } \\
\text { phase }\end{array}$ & $\begin{array}{l}\text { Acute } \\
\text { phase }\end{array}$ & $\begin{array}{l}\text { Remission } \\
\text { phase }\end{array}$ & $\begin{array}{l}\text { Acute } \\
\text { phase }\end{array}$ & $\begin{array}{l}\text { Remission } \\
\text { phase }\end{array}$ & $\begin{array}{l}\text { Acute } \\
\text { phase }\end{array}$ & $\begin{array}{l}\text { Remission } \\
\text { phase }\end{array}$ \\
\hline 1 & $56 / \mathrm{F}$ & Fever & 4 & A & - & Numbness & 1 & 76 & + & + & + & - & + & - & + & - \\
\hline 2 & $28 / \mathrm{M}$ & None & 3 & A & - & Numbness & 4 & 111 & + & - & - & - & - & - & + & - \\
\hline 3 & $21 / \mathrm{M}$ & Diarrhea & 3 & A & - & Numbness & 11 & 95 & + & - & - & - & - & - & + & - \\
\hline 4 & $28 / \mathrm{F}$ & Fever & 4 & A & - & Numbness & 8 & 536 & + & - & + & - & + & - & + & - \\
\hline
\end{tabular}



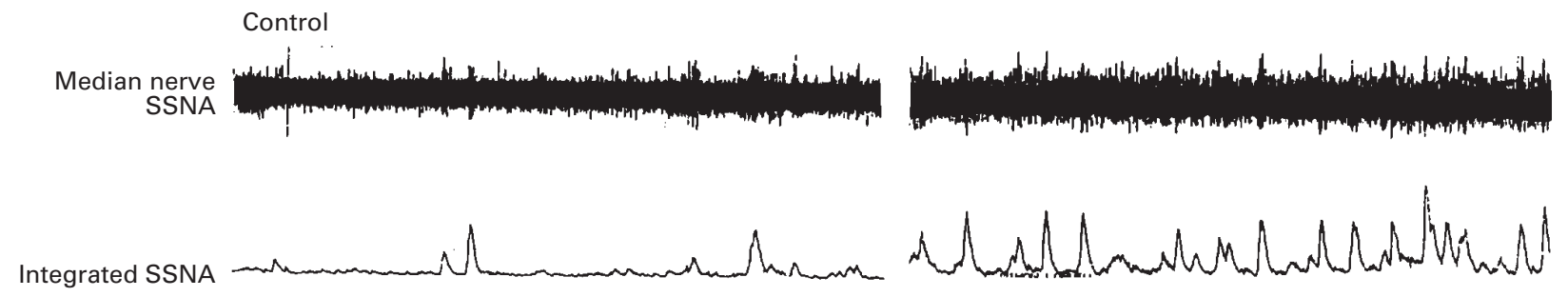

$$
\begin{array}{ll}
\text { Acute phase } & \\
& \text { Case } 1
\end{array}
$$
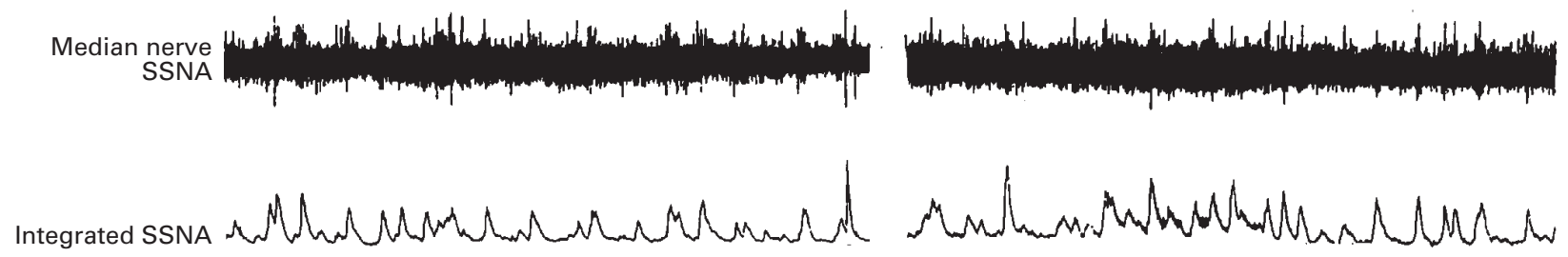

Recovery phase
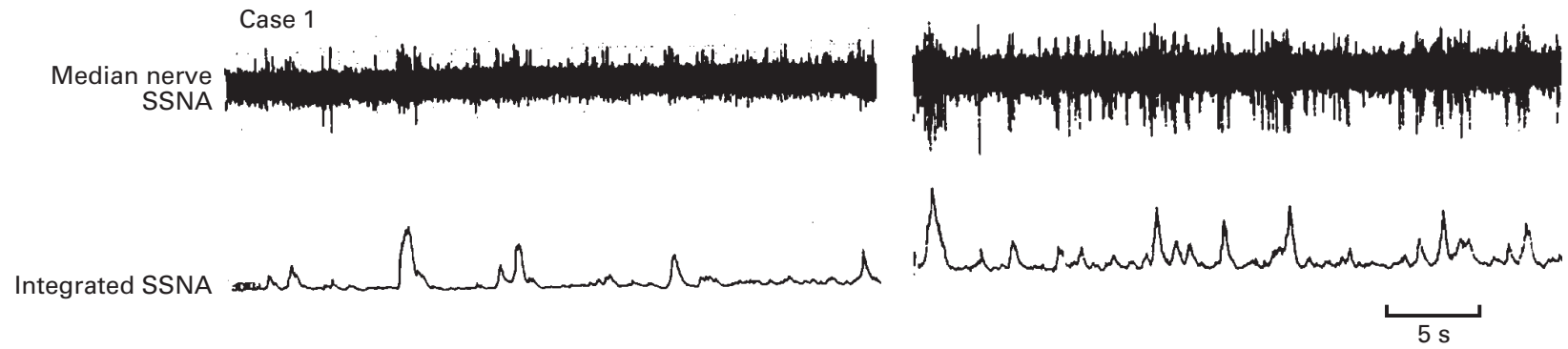

Figure 2 Resting basal SSNA and the SSNA response to stimulation in a patient with Guillain-Barré syndrome and a healthy control (representative cases) Both resting basal SSNA and the SSNA response to cold water stimulation were significantly increased in the patient with Guillain-Barré syndrome compared with the control.

maximal electrical stimulation (applied to the base of the hand using an electrical stimulator), and (4) cold stress (immersion of the both hands in $4^{\circ} \mathrm{C}$ water for one minute). The stimuli were given in the above order with a five minute recovery period between each. During these stimuli, SSNA was continuously recorded. We also monitored in two ways whether the tip of the electrode moved during recording. The first was to assess whether the amplitudes of the integrated neurogram of the reflex bursts at the beginning and at the end of each load were the same. The second was to determine whether the receptive field of afferent nerve combined action potential altered before and after each load. Two recordings were made from each patient, once in the initial phase, and once during the remission phase.

Sixteen healthy volunteers, aged 28 to 70 years (14 men and two women), served as controls.

For comparison between patients with Guillain-Barré syndrome and the control subjects, the significance of differences was assessed using Student's $t$ test, with a significance of $P<0.05$. The slope of the regression line was determined by Spearman's regression analysis. Results are expressed as means (SD).

\section{Results}

Resting basal SSNA was $16.4(0.9)$ bursts/min in the controls and 27.5 (1.1) bursts/min in acute Guillain-Barré syndrome, showing a significant increase in the acute phase of patients with Guillain-Barré syndrome $(\mathrm{P}<0.01)$. It was $15.5(0.3)$ bursts/min in the patients with Guillain-Barré syndrome at remission, similar to the healthy controls. In response to mental arithmetic and acoustic, electrical, and cold water loading tests in acute Guillain-Barré syndrome, the maximum SSNA burst rate was 53.0 (3.0) bursts/min, 41.0 (5.1) bursts/min, 41.1 (3.3) bursts/min, and 51.2 (3.2) bursts/ min respectively. Compared with the healthy controls (27.1 (3.1) bursts/min, 27.2 (1.1) bursts/min, 27.2 (2.1) bursts/min, and 31.1 (2.4) bursts/min, respectively), there was a significant increase of SSNA in acute GuillainBarré syndrome $(\mathrm{P}<0.01)$ (fig 2$)$. The respective values were 28.0 (2.0) bursts/min, 24.3 (1.2) bursts/min, 24.3 (2.3) bursts/min, and 34.1 (1.4) bursts/min at the remission phase of Guillain-Barré syndrome, which were similar to those of control values. When the increase of 

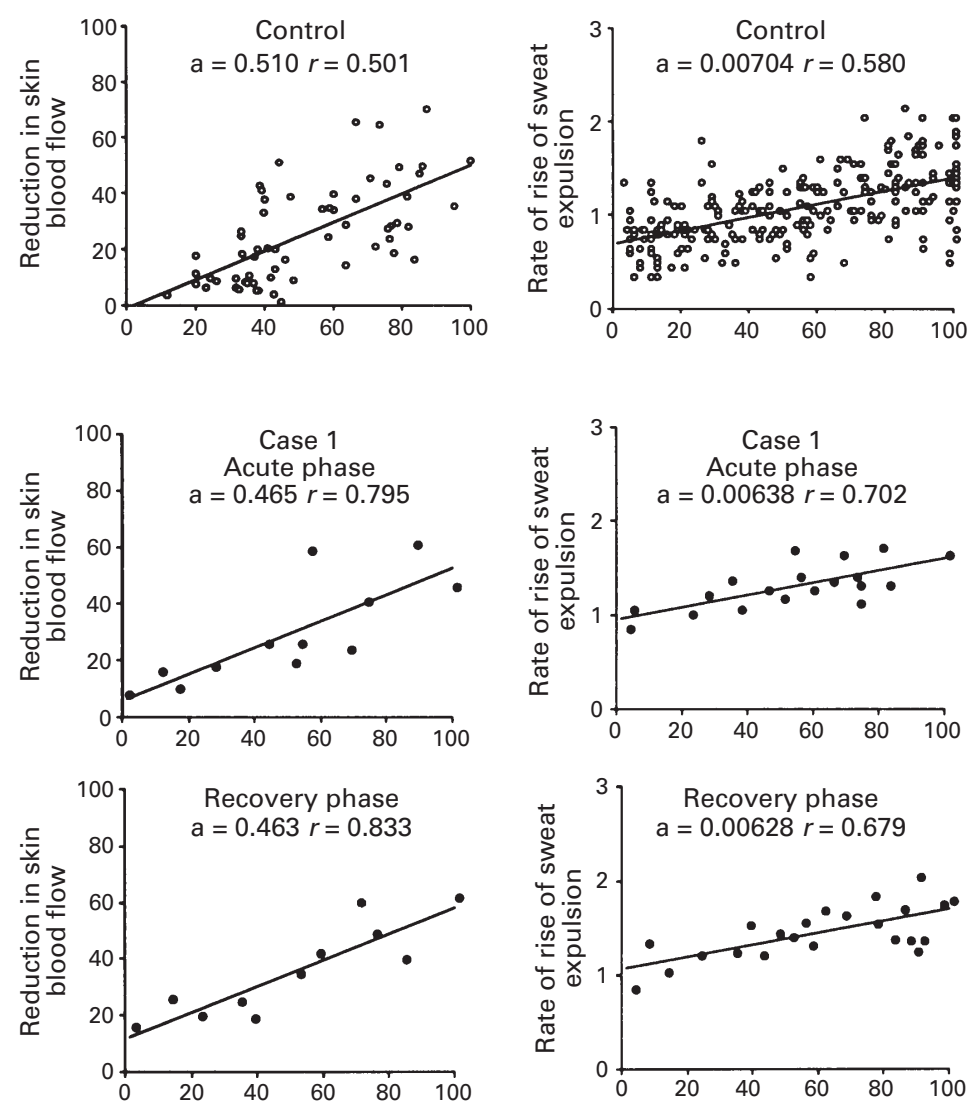

Skin sympathetic nerve activity

Skin sympathetic nerve activity

Figure 3 Effector responses (sweat wave and skin blood flow) to SSNA in a patient with Guillain-Barré syndrome and a healthy control (representative cases) The effector responses are similar in the patient with Guillain-Barré syndrome and control during both the acute and remission phases of the disease.

the SSNA burst rate in response to a loading test was assessed on the basis of the percentage response relative to basal SSNA (the ratio of the maximum response to the resting basal activity), the percentage responses to mental arithmetic and acoustic, electrical, and cold water stimulation were $1.95(0.11), 1.60$ (0.07), 1.35 (0.09), and $1.77(0.06) \%$ respectively, in acute Guillain-Barré syndrome and 1.81 (0.04), 1.55 (0.03), 1.55 (0.10), and 2.19 $(0.05) \%$ in the remission phase, showing no significant differences from those in controls (1.67 (0.31), $1.64(0.25), 1.63$ (0.38), and 1.90 $(0.46) \%)$.

With respect to the correlation between SSNA and the slope of the sweat wave as well as the magnitude of the changes in skin blood flow, the correlation of SSNA with the sweat wave was $r=0.44(0.09)$ in the acute phase and $r=0.63(0.03)$ in the remission stage, showing no significant difference from that in the controls $(r=0.7(0.10))$. The correlation of SSNA with skin blood flow was $r=0.33(0.01)$ in the acute phase and $r=0.47(0.01)$ in the remission stage, again showing no significant difference from the controls $(r=0.51(0.01))$ (fig $3)$.

\section{Discussion}

The present study showed that SSNA was increased in the acute phase of Guillain-Barré syndrome and returned to near normal in the remission stage. In addition, as the relations of effector response rate to SSNA burst rate were constant between the acute and remission stages, some of the autonomic symptoms seen in the acute phase such as palmar hyperhidrosis were not due to the increased effector activity but were due to an increase in SSNA. Fagius et al have shown that MSNA is increased in the acute stage of Guillain-Barré syndrome. ${ }^{16}$ As MSNA is also increased by vagotomy and glossopharyngotomy in normal subjects, they have suggested that the increase of MSNA in the acute phase of Guillain-Barré syndrome may be due to the impairment of the inhibition system for MSNA mediated via the afferent pathways of the vagus and glossopharyngeal nerves. ${ }^{9}$ The present study documented an increase of SSNA in the acute phase of Guillain-Barré syndrome, similarly to MSNA although to a lesser degree, suggesting that there is an extensive and generalised increase of sympathetic nerve activity in the acute phase of Guillain-Barré syndrome. Although the neural regulatory elements that inhibit SSNA have not yet been defined, a slight increase of SSNA was also found after vagotomy and glossopharyngotomy by Fagius et al..$^{19}$ As the increase of SSNA was modest compared with that of MSNA, they proposed that there was no SSNA inhibitory system related to the vagus and glossopharyngeal nerves. Demyelination of the vagus is commonly found in Guillain-Barré syndrome, ${ }^{1}$ so the possibility cannot be ruled out that an increase of SSNA is induced by pathological changes of such inhibitory nerve fibres in the acute phase of Guillain-Barré syndrome. The present study documented that typical patients with Guillain-Barré syndrome with mild to moderate motor dominant disturbances exhibited increased SSNA and autonomic dysfunctions. The pathophysiology of increased SSNA in the acute phase of GuillainBarré syndrome remains to be elucidated, but autonomic dysfunction may develop widely in Guillain-Barré syndrome even in mild cases.

1 Asbury AK. Diagnostic considerations in Guillain-Barré syndrome. Ann Neurol 1981;9(suppl): 1-5

2 Halls J, Bredkjær C, Friis ML. Guillain-Barré syndrome: diagnostic criteria, epidemiology, clinical course and prognosis. Acta Neurol Scand 1988;78:118-22.

3 Ropper AH, Wijdicks EFM. Blood pressure fluctuations in the dysautonomia of Guillain-Barré syndrome. Arch Neurol 1990;47:706-8.

4 Singh NK, Jaiswal AK, Misra S, et al. Assessment of autonomic dysfunction in Guillain-Barré syndrome and its

prognostic implication. Acta Neurol Scand 1987;75:101-5. Panegyres PK, Mastaglia FL. Guillain-Barre syndrome with
involvement of the central and autonomic nervous systems. Med f A ust 1989;150:655-9.

6 McLeod JG, Tuck RR. Disorders of the autonomic nervous system: part 1. pathophysiology and clinical features. Ann system: part 1. pathophysi
Neurol 1987;21:419-430.

7 Ahmad J, Kham AS, Siddiqui MA, et al. Estimation of plasma and urinary catecholamines in Guillain-Barré syndrome. Fpn F Med 1985;24:24-9.

8 Calleja MA. Autonomic dysfunction and Guillain-Barré syndrome: the use of esmolol in its management. Anaesthesia 1990;45:736-7.

9 Fagius J, Wallin BG. Microneurographic evidence of excessive sympathetic outflow in the Guillain-Barré syndrome. Brain 1983;106:589-600.

10 Wallin BG. Intraneural recordings of normal and abnormal sympathetic activity in man. In: Bannister R, Mathias CJ, eds. Autonomic failure. A textbook of clinical disorders of the eds. Autonomic failure. A textbook of clinical disorders of the
autonomic nervous system. 3rd ed. London: Oxford Univerautonomic nervous system.
sity Press, 1992:359-77.

11 Iwase S, Mano T, Sugenoya J, et al. Relationships among skin sympathetic nerve activity, sweating and skin bloodflow. Environmental Medicine 1988;32:55-67. 
12 Okamoto T, Iwase S, Sugenoya J, et al. Different thermal dependency of cutaneous sympathetic outflow to glabrous 4 .

13 Sugenoya J, Iwase S, Mano $\mathrm{T}$, et al. Identification of sudomotor activity in cutaneous sympathetic nerves using sweat expulsion as the effector response. Eur 7 Appl Physiol 1990;61:302-8

14 Iwase S, Mano T, Sugenoya J, et al. Microneurographic study on sympathetic control of sweating and skin blood flow. In: Mabuchi K, Harwood A, Chur B, eds. Advanced techniques and clinical applications in biomedical thermology. 1994:147-62.

15 Hagbarth K-E, Hallin RG, Hongell A, et al. General characteristics of sympathetic activity in human skin nerves. Acto Physiol Scand 1972;84:164-76.
16 Murakami K, Sobue G, Iwase S, et al. Skin sympathetic nerve activity in acquired idiopathic generalized anhidrrosis. Neurology 1993;43:1137-9.

17 Yamamoto K, Sobue G, Iwase S, et al. Possible mechanism of anhidrosis in a symptomatic female carrier of Fabry's disease: an assessment by skin sympathetic nerve activity and sympathetic skin response. Clin Auton Res 1996;6:10710.

18 Kumazawa K, Sobue G, Yamamoto K, et al. Segmental anhidrosis in the spinal dermatomes in Sjögren's syndrome-associated neuropathy. Neurology 1993;43: 1820-3.

19 Fagius J, Wallin BG, Sundlöf G, et al. Sympathetic outflow in man after anaesthesia of the glossapharyngeal and vagus nerves. Brain 1985;108:423-38.

\section{Fournal of Neurology Neurosurgery and Psychiatry - http://www.jnnp.com}

Visitors to the world wide web can now access the fournal of Neurology Neurosurgery and Psychiatry either through the BMJ Publishing Group's home page (http://www.bmjpg.com) or directly by using its individual URL (http:/ /www.jnnp.com). There they will find the following:

- Current contents list for the journal

- Contents lists of previous issues

- Members of the editorial board

- Subscribers' information

- Instructions for authors

- Details of reprint services.

A hotlink gives access to:

- BMJ Publishing Group home page

- British Medical Association web site

- Online books catalogue

- BMJ Publishing Group books.

The web site is at a preliminary stage and there are plans to develop it into a more sophisticated site. Suggestions from visitors about features they would like to see are welcomed. They can be left via the opening page of the BMJ Publishing Group site or, alternatively, via the journal page, through "about this site". 